\title{
Recession Rumblings
}

\author{
Kevin L. Kliesen
}

A fter growing at a robust 5.6 percent annual rate in the first quarter of 2006, the pace of U.S. economic growth has subsequently downshifted. Real GDP rose at a 1.3 percent annual rate in 2007:Q1, after increasing at a 2.3 percent rate over the final three quarters of 2006. Although business cycle turning points are notoriously difficult to forecast, most professional economic forecasters do not expect the economy to slide into a recession any time soon. Indeed, the consensus of most professional forecasters is that real GDP growth will slowly accelerate to around 3 percent by the end of 2007 .

U.S. business cycle peaks and troughs are determined by the Business Cycle Dating Committee of the National Bureau of Economic Research (NBER). Their approach is to look at a few key monthly variables when determining if the economy has transitioned from a business expansion to a recession, or vice versa. Because much of the data the NBER looks at is volatile and subject to numerous revisions, the Committee typically determines the peak or trough several months after the fact.

Many academic researchers, striving for a more timely method, have developed alternative approaches. Some of these are forwardlooking, while some try to date business cycle peaks and troughs contemporaneously. ${ }^{1}$ Among the latter are a class of "Markov switching models," originally developed by James Hamilton of the University of California at San Diego. In brief, one version of these models estimates the probability of a data series being in one of two states: expansion or recession. The trick, then, is picking a data series that exhibits distinct cyclical properties. ${ }^{2}$ Nonfarm payroll employment and industrial production are two such indicators. According to this model, using either of these indicators, the probability of the economy being in a recessionary state in March 2007 was less than 2 percent.

Another variable that exhibits cyclical characteristics is the spread between yields on 10-year and 3-month Treasury securities, otherwise known as the yield curve. Typically, the yield curve has inverted-that is, short-term interest rates have risen above long-term rates-before most postwar recessions. Hence, some economists view the current inversion of the yield curve (since August 2006) as an ominous sign.

The chart shows an alternative method of identifying business cycle peaks and troughs: Each observation is the number of stories appearing each month in the printed editions of the New York Times and Wall Street Journal that mention "recession." 3 The rationale for this indicator is that periods of below-trend growth of sales, production, employ- ment, and profits spur an increased awareness of the possibility of a recession developing. This awareness shows up as recession chatter in the financial press.

There are a few things to notice in the chart: First, "recession" stories seem to exhibit normal business cycle characteristics; the number of stories rises during periods of slow growth and recession and remains low during periods of economic expansion. Second, recession stories seem to peak toward the end of the recession, or shortly after, and then fall sharply-which suggests that this indicator might be useful in helping identify troughs, though perhaps less so for peaks. Third, although the two newspaper counts show a high degree of correlation (0.86), the number of recession stories that appear in the New York Times is usually larger than the number that appear in the Wall Street Journal. This was particularly evident in the 1973-75 and the 1990-91 recessions. Finally, despite a noticeable jump in the number of "recession stories" in the Wall Street Journal in March 2007, both series remain at levels consistent with economic expansion.

\footnotetext{
${ }^{1}$ John Fernald and Bharat Trehan, "Is a Recession Imminent?" Federal Reserve Bank of San Francisco Economic Letter, Number 2006-32, 11/24/06.

2 Marcelle Chauvet and Jeremy M. Piger, "Identifying Business Cycle Turning Points in Real Time," Federal Reserve Bank of St. Louis Review, March/April 2003, 85(2), pp. 47-61.

3 The data series was constructed from the Factiva and Proquest databases. I thank Katrina Stierholz for her assistance.
}

\section{Number of Newspaper Stories with the Word "Recession"}

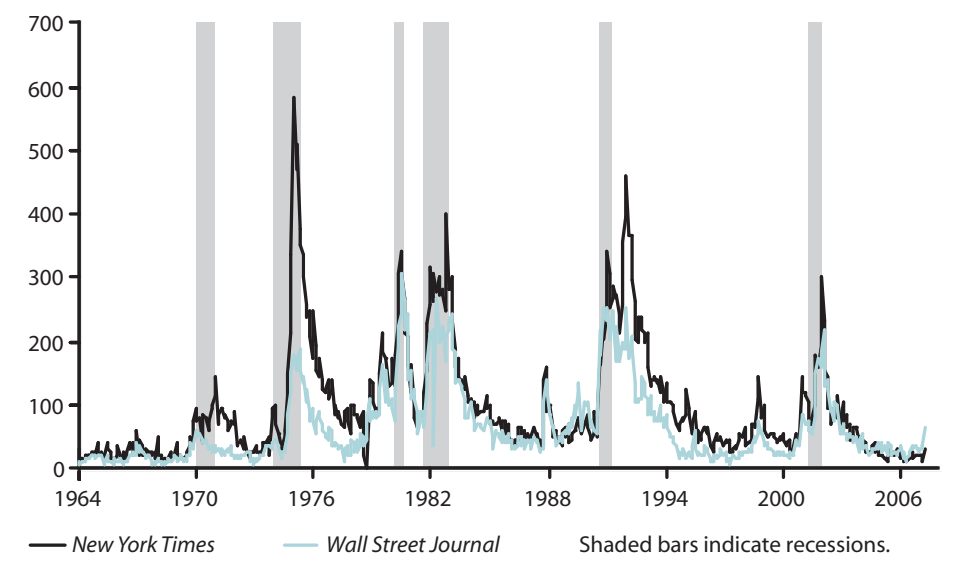

Views expressed do not necessarily reflect official positions of the Federal Reserve System. 